\title{
Gapless spin liquid of an organic triangular compound evidenced by thermodynamic measurements
}

\author{
Satoshi Yamashita1,2, Takashi Yamamoto1, Yasuhiro Nakazawa, ${ }^{1,3}$, Masafumi Tamura ${ }^{4}$ Reizo Kato²
}

In frustrated magnetic systems, long-range ordering is forbidden and degeneracy of energy states persists, even at extremely low temperatures. Under certain conditions, these systems form an exotic quantum spin-liquid ground state, in which strongly correlated spins fluctuate in the spin lattices. Here we investigate the thermodynamic properties of an anion radical spin liquid of $\mathrm{EtMe}_{3} \mathrm{Sb}\left[\mathrm{Pd}(\mathrm{dmit})_{2}\right]_{2}$, where dmit represents 1,3-dithiole-2-thione-4,5-dithiolate. This compound is an organic dimer-based Mott insulator with a two-dimensional triangular lattice structure. We present distinct evidence for the formation of a gapless spin liquid by examining the $T$-linear heat capacity coefficient, $\gamma$, in the low-temperature heat capacity. Using comparative analyses with $\mathrm{\kappa}-(\mathrm{BEDT}-\mathrm{TTF})_{2} \mathrm{Cu}_{2}(\mathrm{CN})_{3}$, a generalized picture of the new spin liquid in dimer-based organic systems is discussed. We also report anomalous enhancement of $\gamma$, produced by a kind of criticality inherent to the $\mathrm{Pd}(\mathrm{dmit})_{2}$ phase diagram.

\footnotetext{
'Department of Chemistry, Graduate School of Science, Osaka University, Machikaneyama 1-1, Toyonaka, Osaka 560-0043, Japan. ${ }^{2}$ RIKEN, Hirosawa 2-1, Wako, Saitama 351-0198, Japan. ${ }^{3}$ Institute for Molecular Science, Nishigonaka 38, Myodaiji, Okazaki 444-8585, Japan. ${ }^{4}$ Department of Physics, Faculty of Science and Technology, Tokyo University of Science, Yamazaki, Noda, Chiba 278-8510, Japan. Correspondence and requests for materials should be addressed to Y.N. (email: nakazawa@chem.sci.osaka-u.ac.jp).
} 
$\mathrm{T}$ he formation of a spin-liquid ground state in frustrated systems is a macroscopic manifestation of quantum phenomena associated with spin degrees of freedom. Numerous studies have investigated the nature of this fluctuating spin state at low energies $^{1-4}$. Theoretical studies predict new possibilities for the ground state, namely, the long-range resonating valence bond (RVB) state, which is expressed by numerous singlet bonds resonating in the lattice ${ }^{4}$ and other spin liquids with small-gap or gapless character in their low-energy excitations ${ }^{1-3}$. Recent advances in material syntheses and characterization techniques have resulted in various new spin liquids being produced. Two-dimensional triangular lattice compounds such as $\mathrm{Cs}_{2} \mathrm{CuCl}_{4}(S-1 / 2)^{5}, \mathrm{NiGa}_{2} \mathrm{~S}_{4}(S-1)^{6}$ and $\kappa$-(BEDTTTF $)_{2} \mathrm{Cu}_{2}(\mathrm{CN})_{3}(S-1 / 2)^{7}$ and Kagomé lattices of $\mathrm{SrCr}_{9 \mathrm{p}} \mathrm{Ga}_{12-9 \mathrm{p}} \mathrm{O}_{19}$ $(S-3 / 2)^{8}$, volborthite $(S-1 / 2)^{9}$, herbertsmithite $(S-1 / 2)^{10}$ and vesigniete $(S-1 / 2)^{11}$ have stimulated extensive research. More recently, a spin-liquid state in a hyper-Kagomé lattice compound of $\mathrm{Na}_{4} \mathrm{Ir}_{3} \mathrm{O}_{8}$ $(S-1 / 2)^{12}$ was observed, enabling frustration physics in a $3 \mathrm{D}$ system to be investigated. Fundamental studies to understand the intrinsic nature of spin liquids and their related physical properties are advancing rapidly ${ }^{13}$.

Among these spin-liquid materials, an organic compound of $\mathrm{K}$ (BEDT-TTF $)_{2} \mathrm{Cu}_{2}(\mathrm{CN})_{3}$ offer unique insights into frustration physics. It is a dimer-based molecular Mott insulator with a two-dimensional structure. The electronic properties are dominated by strong magnetic interactions, $|J| / k_{\mathrm{B}}$, larger than $200 \mathrm{~K}^{7}$. In this compound, spin-liquid nature has been observed by ${ }^{13} \mathrm{C}-\mathrm{NMR}^{7}$, heat capacity $^{14}$ and thermal transport ${ }^{15}$ measurements. Although the gapless feature of the low-energy excitations is reported by the heat capacity measurement ${ }^{14}$, thermal transport result implies a possibility of a tiny gap opening with an order of $0.5 \mathrm{~K}^{15}$. A possible relation with the superconductivity of conductive $\pi$-electrons and coupling with charge degrees of freedom in the dimer unit ${ }^{16}$ are stimulating extensive interest in frustration problems and electron correlations. Recently, an anion radial compound of $\mathrm{EtMe}_{3} \mathrm{Sb}\left[\mathrm{Pd}(\mathrm{dmit})_{2}\right]_{2}$ has been reported as another candidate of organic quantum spin-liquid material by magnetic susceptibility ${ }^{17},{ }^{13} \mathrm{C}-\mathrm{NMR}^{18,19}$ and thermal conductivity ${ }^{20}$ measurements. EtMe $\mathrm{Sb}\left[\mathrm{Pd}(\mathrm{dmit})_{2}\right]_{2}$ consists of an anion of an acceptor molecule $\mathrm{Pd}(\mathrm{dmit})_{2}$ and a countercation $\mathrm{EtMe}_{3} \mathrm{Sb}^{+}$. Dimerized $\left[\mathrm{Pd}(\mathrm{dmit})_{2}\right]_{2}{ }^{-}$anions form a segregated stacking structure in a crystal lattice with space group $C 2 / c$ and a quasi-twodimensional $\pi$-electron system is established in it $^{21}$. Figure la shows the molecular structure of $\mathrm{Pd}(\mathrm{dmit})_{2}$ and crystal packing in the $2 \mathrm{D}$ plane. As the energy gap between the highest occupied molecular orbital (HOMO) and the lowest unoccupied molecular orbital (LUMO) is small, an electron spin localized on each dimer originates from the antibonding $\mathrm{HOMOs}^{22}$. The $d$-orbital of the Pd ion makes a negligible contribution to the HOMO and thus does not contribute to the spin density. By changing the central pnictogen atom and the numbers of methyl $(\mathrm{Me})$ and ethyl (Et) groups in countercations, the ratio of the transfer integrals between the dimers $\left(t_{\mathrm{r}}=\right) t^{\prime} / t\left(=t_{\mathrm{s}} \approx t_{\mathrm{B}}\right)$ shown in the inset of Figure 1a can be tuned from the antiferromagnetic $(\mathrm{AF})$ region to the charge-ordered $(\mathrm{CO})$ region in the phase diagram ${ }^{23}$. Tight-binding calculations based on the crystallographic data at room temperature suggest that the compound of $\mathrm{EtMe}_{3} \mathrm{Sb}\left[\mathrm{Pd}(\mathrm{dmit})_{2}\right]_{2}$ is located at $t^{\prime} / t=0.92$, which implies that a nearly ideal triangle structure is realized ${ }^{18,24}$. This compound is similar to $\mathrm{K}$-(BEDT-TTF $)_{2} \mathrm{Cu}_{2}(\mathrm{CN})_{3}$; they are Mott insulators with a layered structure consisting of a triangular lattice of dimers. The remarkable structural feature of $\mathrm{EtMe}_{3} \mathrm{Sb}\left[\mathrm{Pd}(\mathrm{dmit})_{2}\right]_{2}$ is that it has a stacking direction of acceptor molecules, shown in Figure 1a, which is a characteristic factor in discussing the $\mathrm{Pd}(\mathrm{dmit})_{2}$ compounds.

In this study, we report the low-temperature thermodynamic nature of $\mathrm{EtMe}_{3} \mathrm{Sb}\left[\mathrm{Pd}(\mathrm{dmit})_{2}\right]_{2}$ focusing on the low-energy excitations from the ground state. From the thermodynamic data, we assert that the ground state is a gapless spin liquid characterized by the existence of a distinct $T$-linear heat capacity term. Comparative a

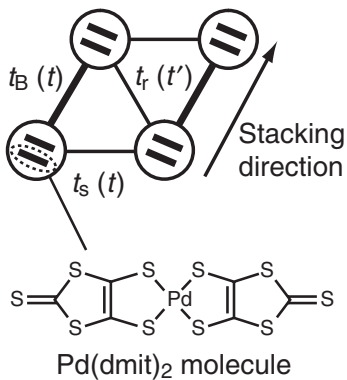

b

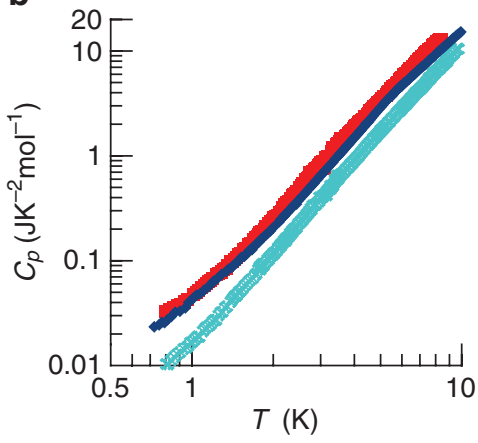

Figure 1 | Temperature dependences of heat capacities of $\mathrm{EtMe}_{3} \mathrm{Sb}\left[\mathrm{Pd}(\mathrm{dmit})_{2}\right]_{2}$ and its related salts. (a) A schematic illustration of the molecular arrangement in the acceptor plane of $\mathrm{EtMe}_{3} \mathrm{Sb}\left[\mathrm{Pd}(\mathrm{dmit})_{2}\right]_{2}$ (upper) and molecular structure of $\mathrm{Pd}(\mathrm{dmit})_{2}$ (lower). The longer axis of the molecule is arranged perpendicular to the plane. $\mathrm{Pd}(\mathrm{dmit})_{2}$ molecules form a dimerized structure, which is indicated by the circle. The dimers form a triangular lattice structure. The definition of three transfer integrals between neighbouring dimers $\left(t_{\mathrm{B}}, t_{\mathrm{r}}, t_{\mathrm{s}}\right)$ of $\mathrm{Pd}(\mathrm{dmit})_{2}$ systems is shown in the upper figure. The magnitude of these transfers is $\left(t_{\mathrm{r}}=\right) t^{\prime} / t\left(=t_{\mathrm{s}} \approx t_{\mathrm{B}}\right)$ and if $t^{\prime} / t=1$, a regular triangular system is established. The stacking direction of $\mathrm{Pd}(\mathrm{dmit})_{2}$ molecules is shown by the arrow. (b) The data of $\mathrm{EtMe}_{3} \mathrm{Sb}\left[\mathrm{Pd}(\mathrm{dmit})_{2}\right]_{2}$ (red squares), EtMe $\mathrm{P}\left[\mathrm{Pd}(\mathrm{dmit})_{2}\right]_{2}\left(\mathrm{P} 2_{1} / \mathrm{m}\right.$ : aqua blue crosses) and $\kappa$-(BEDT-TTF) ${ }_{2} \mathrm{Cu}_{2}(\mathrm{CN})_{3}$ (blue diamonds) are plotted on a logarithmic scale. The heat capacities of spin-liquid compounds $\mathrm{EtMe}_{3} \mathrm{Sb}\left[\mathrm{Pd}(\mathrm{dmit})_{2}\right]$ and $\mathrm{\kappa}-(\mathrm{BEDT}-\mathrm{TTF})_{2} \mathrm{Cu}_{2}(\mathrm{CN})_{3}$ are larger than those of $\mathrm{EtMe}_{3} \mathrm{P}\left[\mathrm{Pd}(\mathrm{dmit})_{2}\right]_{2}$ with ordered ground state due to the spin entropy remains at low temperatures in the former two compounds. The realization of the spin-liquid state is suggested in $\mathrm{EtMe}_{3} \mathrm{Sb}\left[\mathrm{Pd}(\mathrm{dmit})_{2}\right]_{2}$

discussions on the Wilson ratio, $R_{\mathrm{W}}$, and a hump-like structure with $\kappa$-(BEDT-TTF $)_{2} \mathrm{Cu}_{2}(\mathrm{CN})_{3}$ reveal that the spin liquids of organic compounds have similar characters. Our low-temperature heat capacity data of deuterated $\mathrm{EtMe}_{3} \mathrm{Sb}\left[\mathrm{Pd}(\mathrm{dmit})_{2}\right]_{2}$ imply a possible enhancement of heat capacity around the quantum critical region of the $\mathrm{AF}$ and spin liquid in the phase diagram.

\section{Results}

Heat capacities of EtMe $3 \mathbf{S b}\left[\mathrm{Pd}(\mathrm{dmit})_{2}\right]_{2}$ and its analogues. The temperature dependence of the heat capacity of $\mathrm{EtMe}_{3} \mathrm{Sb}\left[\mathrm{Pd}(\mathrm{dmit})_{2}\right]_{2}$ obtained by measuring several crystals is shown in Figure $1 \mathrm{~b}$. The heat capacities are plotted on a logarithmic scale against temperature. Data for $\mathrm{\kappa}$-(BEDT-TTF $)_{2} \mathrm{Cu}_{2}(\mathrm{CN})_{3}{ }^{14}$ are also displayed in the figure, which show qualitatively similar temperature dependence. The heat capacity of $\mathrm{EtMe}_{3} \mathrm{Sb}\left[\mathrm{Pd}(\mathrm{dmit})_{2}\right]_{2}$ has no sharp peak structure. This result indicates absence of long-range orderings over the entire measured temperature range. Figure $1 \mathrm{~b}$ also displays data for $\mathrm{EtMe}_{3} \mathrm{P}\left[\mathrm{Pd}(\mathrm{dmit})_{2}\right]_{2}\left(P 2_{1} / \mathrm{m}\right)$, which has a non-magnetic ground state with valence bond solid (VBS) type ordering at $25 \mathrm{~K}^{23,25}$. The heat capacity values, for example, $42.8 \mathrm{~mJ} \mathrm{~K}^{-1} \mathrm{~mol}^{-1}$ at $1 \mathrm{~K}$ and $115 \mathrm{~mJ} \mathrm{~K}^{-1} \mathrm{~mol}^{-1}$ at $4 \mathrm{~K}$ of $\mathrm{EtMe}_{3} \mathrm{Sb}\left[\mathrm{Pd}(\mathrm{dmit})_{2}\right]_{2}$, which are relatively higher than those for $\mathrm{EtMe}_{3} \mathrm{P}\left[\mathrm{Pd}(\mathrm{dmit})_{2}\right]_{2}$, indicate that magnetic entropy survives at low temperature owing to fluctuations of correlated spins. The absence of thermal anomalies is consistent with the magnetic susceptibility measurement down to $5 \mathrm{~K}$ performed by Tamura and Kato ${ }^{17}$ and the ${ }^{13} \mathrm{C}$-NMR spectrum down to $19.4 \mathrm{mK}$ measured by Itou et al. ${ }^{18,19}$

To elucidate the detailed characteristics of low-energy excitations from the ground state, data in the low-temperature region are plotted as $C_{p} T^{-1}$ vs $T^{2}$ in Figure 2a. Fitting the 0 -T data between 0.9 and $2.0 \mathrm{~K}$ for $\mathrm{EtMe}_{3} \mathrm{Sb}\left[\mathrm{Pd}(\mathrm{dmit})_{2}\right]_{2}$ using the formula 

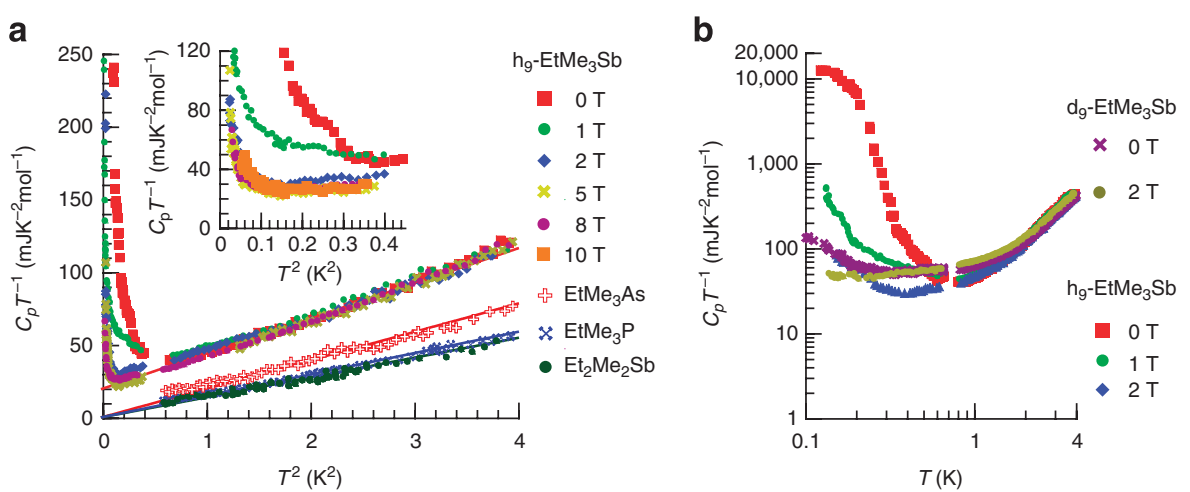

Figure 2 | Low-temperature heat capacities of EtMe $\mathbf{E}_{3} \mathbf{S b}\left[\mathbf{P d}(\mathbf{d m i t})_{2}\right]_{\mathbf{2}^{*}}$ (a) $C_{p} T^{-1}$ versus $T^{2}$ plot of $\mathrm{EtMe}_{3} \mathrm{Sb}\left[\mathrm{Pd}(\mathrm{dmit})_{2}\right]_{2}\left(\mathrm{~h}_{9}-\mathrm{EtMe} \mathrm{e}_{3} \mathrm{Sb}\right)$ below $2 \mathrm{~K}$ obtained under OT (red squares), 1T (green filled circles), 2T (blue diamonds), $5 \mathrm{~T}$ (ocher crosses) and $8 \mathrm{~T}$ (purple filled circles). This figure contains the data of related $\mathrm{Pd}(\mathrm{dmit})_{2}$ salts of EtMe $\left.\mathrm{E}_{3} \mathrm{As}\left[\mathrm{Pd}(\mathrm{dmit})_{2}\right]_{2}\left(\mathrm{EtMe}_{3} \mathrm{As} \text { red pluses), EtMe } \mathrm{P}_{3} \mathrm{P}\left[\mathrm{Pd}(\mathrm{dmit})_{2}\right]_{2}\left(\mathrm{EtMe}_{3} \mathrm{P} \text { blue crosses}\right) \text { and } \mathrm{Et}_{2} \mathrm{Me}_{2} \mathrm{Sb}_{2} \mathrm{Pd}_{(\mathrm{dmit}}\right)_{2}\right]_{2}\left(\mathrm{Et}_{2} \mathrm{Me}_{2} \mathrm{Sb}\right.$ green filled circles), which have ordered ground states for comparison. The fitting lines obtained by using the data of OT of each salt are shown by the same colours with the data. The existence of a $T$-linear contribution even in the insulating state of $\mathrm{EtMe}_{3} \mathrm{Sb}\left[\mathrm{Pd}(\mathrm{dmit})_{2}\right]_{2}$ is observed. A large upturn below $1 \mathrm{~K}$ that masks the information of the electron spins is probably attributable to the rotational tunnelling of Me groups. The inset figure shows $C_{p} T^{-1}$ versus $T^{2}$ plot of EtMe $\left.\mathrm{Sb}_{3} \mathrm{Pd}(\mathrm{dmit})_{2}\right]_{2}$ data below $0.7 \mathrm{~K}$, where a large upturn with magnetic field dependence appears. The data obtained under $0 \mathrm{~T}$ (red squares), $1 \mathrm{~T}$ (green filled circles), 2T (blue diamonds), $5 \mathrm{~T}$ (ocher crosses), $8 \mathrm{~T}$ (purple filled circles) and 10 T (orange squares) are plotted. (b) The overall behaviour of $C_{p} T^{-1}$ below $4 \mathrm{~K}$ of EtMe $3 \mathrm{Sb}\left[\mathrm{Pd}(\mathrm{dmit})_{2}\right]_{2}\left(\mathrm{~h}_{9}-\mathrm{EtMe}_{3} \mathrm{Sb}\right)$ and its deuterated compound of $\mathrm{d}_{9}-\mathrm{EtMe}_{3} \mathrm{Sb}\left[\mathrm{Pd}(\mathrm{dmit})_{2}\right]_{2}\left(\mathrm{~d}_{9}-\mathrm{EtMe} \mathrm{e}_{3} \mathrm{Sb}\right)$ in a logarithmic plot. The data under OT (red squares), $1 \mathrm{~T}$ (green filled circles) and $2 \mathrm{~T}$ (blue diamonds) of $\mathrm{EtMe}_{3} \mathrm{Sb}\left[\mathrm{Pd}(\mathrm{dmit})_{2}\right]_{2}$ is shown by the same symbols as in (a). The data obtained under OT (purple crosses) and $2 \mathrm{~T}$ (ocher filled circles) of $\mathrm{d}_{9}$-EtMe $\mathrm{E}_{3} \mathrm{Sb}\left[\mathrm{Pd}(\mathrm{dmit})_{2}\right]_{2}$ are compared in the same plot. The upturn has been reduced down to about few percent by deuteration. The origin of the upturn is extrinsic for the discussion of electronic spins and is attributed to the existence of rotational tunnelling levels of Me groups in the cation.

$C_{p} T^{-1}=\gamma+\beta T^{2}$ gives $\gamma=19.9 \mathrm{~mJ} \mathrm{~K}^{-2} \mathrm{~mol}^{-1}$ and $\beta=24.1 \mathrm{mJK}^{-4} \mathrm{~mol}^{-1}$. The finite electronic heat capacity coefficient $\gamma$ in a triangular $S-1 / 2$ spin system suggests that gapless excitations occur from a liquidlike ground state, similar to the case of $\kappa$-(BEDT-TTF $)_{2} \mathrm{Cu}_{2}(\mathrm{CN})_{3}{ }^{14}$. As Figure $2 \mathrm{a}$ shows, $\gamma$ is not seriously affected by magnetic fields up to $8 \mathrm{~T}$. This excludes the possibility that paramagnetic impurity spins are the origin of the $\gamma$ term. The measurement was also performed for over 50 pieces of microcrystals, and the temperature and magnetic field dependences obtained were almost the same as those in Figure 2a. Thus, the large heat capacity at low temperatures is attributed to the intrinsic properties of this material.

To disclose peculiarity in the thermodynamic properties due to spin frustration, Figure $2 \mathrm{a}$ also shows the data for two other analogous compounds $\mathrm{EtMe}_{3} \mathrm{As}\left[\mathrm{Pd}(\mathrm{dmit})_{2}\right]_{2}$ and $\mathrm{Et}_{2} \mathrm{Me}_{2} \mathrm{Sb}\left[\mathrm{Pd}(\mathrm{dmit})_{2}\right]_{2}$, together with the data for $\mathrm{EtMe}_{3} \mathrm{P}\left[\mathrm{Pd}(\mathrm{dmit})_{2}\right]_{2}$. These salts have ordered ground states as are assorted by their transfer energy ratios $t^{\prime} / t$. $\mathrm{EtMe}_{3} \mathrm{P}\left[\mathrm{Pd}(\mathrm{dmit})_{2}\right]_{2}$ has a nonmagnetic VBS state below $25 \mathrm{~K}^{25}$, whereas $\mathrm{EtMe}_{3} \mathrm{As}\left[\mathrm{Pd}(\mathrm{dmit})_{2}\right]_{2}$ has an antiferromagnetic long-range ordering at $23 \mathrm{~K}^{26}$. $\mathrm{Et}_{2} \mathrm{Me}_{2} \mathrm{Sb}\left[\mathrm{Pd}(\mathrm{dmit})_{2}\right]_{2}$ undergoes a drastic firstorder transition accompanied by $\mathrm{CO}$ at $70 \mathrm{~K}^{27}$. From the figure, it is evident that these salts with ordered ground states have lower heat capacities than $\mathrm{EtMe}_{3} \mathrm{Sb}\left[\mathrm{Pd}(\mathrm{dmit})_{2}\right]_{2}$. Linear extrapolation of the data to $T=0$ gives a vanishing $\gamma$ term in the heat capacity. This fact demonstrates that the $T$-linear contribution is observed only in the spin-liquid system.

Heat capacity of $\mathrm{EtMe}_{3} \mathrm{Sb}\left[\mathrm{Pd}(\mathrm{dmit})_{2}\right]_{2}$ below $1 \mathrm{~K}$. As frustrated spin systems may undergo unexpected phase changes in the lowenergy region due to various kinds of many-body effects, thermodynamic measurements should be performed at temperatures as low as possible. In Figure 2a, we also show heat capacity data obtained in the dilution temperature region in the $C_{p} T^{-1}$ vs $T^{2}$ plot. These data are displayed in the inset of Figure $2 \mathrm{a}$, wherein a low-temperature region is expanded in the same plot. Unexpectedly, a large upturn below $1 \mathrm{~K}$ masks information about the electron spins. The magnetic fields tend to reduce this upturn, which is an unusual behaviour as a simple Schottky-type heat capacity due to nuclear spins. Figure $2 b$ is a logarithmic plot that shows the overall behaviour of $C_{p} T^{-1}$ below $4 \mathrm{~K}$. The most plausible explanation for this upturn is rotational motion of methyl (Me) groups in the cation layer. The $\mathrm{Me}$ groups have a hindered rotation due to quantum tunnelling in the threefold symmetry potential $\left(C_{3}\right)$ at low temperatures. The energy levels of the quantum tunnelling states are expressed by irreducible representation of $A, E$, and there exists a small energy splitting expressed by $\Delta$ between them. These levels are coupled with nuclear spin states of three protons in the Me group. If the proton spins are in equilibrium condition, the total nuclear spins for $A$ and $E$ states should be $I=3 / 2$ and $I=1 / 2$, respectively. The energy splitting $(\Delta)$ is usually very small, in the order of $10^{0-2} \mu \mathrm{eV}$, and therefore produces an increase of heat capacity corresponding to the hightemperature tail of the Schottky anomaly below $1 \mathrm{~K}$, as is studied by Sorai et al. in some metal complexes containing Me groups ${ }^{28}$. The upturn observed in $\mathrm{EtMe}_{3} \mathrm{Sb}\left[\mathrm{Pd}(\mathrm{dmit})_{2}\right]_{2}$ is considered to have the same origin. Application of a magnetic field may cause a hyperfine splitting of the nuclear spins and it consequently creates magneticfield dependence in $C_{p}$. However, spin inversion of protons in such organic salts has a rather long spin-lattice relaxation time, in the order of $10^{1-3} \mathrm{~s}$, so that it cannot be detected accurately by thermal relaxation calorimetry technique, in which we usually analyse temperature relaxation behaviours in the similar time scale. The unusual magnetic field dependence of this Schottky anomaly under magnetic fields observed in this compound is probably related to the behaviours of nuclear spin levels and to the long time constant of proton spin inversion. This remains speculative because, to the best of our knowledge, the detailed magnetic-field dependence of the heat capacity has not been investigated experimentally. However, the unexpectedly large heat capacity, which is comparable to the electron spin entropy in this limited temperature region, suggests that it should be considered separately from the electronic system.

The estimation of $\gamma$ using the dilution temperature data does not reveal any change, which implies that the $T$-linear term with 
$\gamma=19.9 \mathrm{~mJ} \mathrm{~K}^{-2} \mathrm{~mol}^{-1}$ is intrinsic for this material. The $C_{p} T^{-1}$ vs $T^{2}$ plots in Figure $2 \mathrm{a}$ for $\mathrm{EtMe}_{3} \mathrm{Sb}\left[\mathrm{Pd}(\mathrm{dmit})_{2}\right]_{2}$ under relatively strong magnetic fields of $8 \mathrm{~T}$ in the ${ }^{3} \mathrm{He}$ region and up to $10 \mathrm{~T}$ in the dilution temperature region do not reveal any significant change in the $\gamma$ term. A $T$-linear term of the low-temperature heat capacity with a similar magnitude was reported for $\kappa$-(BEDT-TTF $)_{2} \mathrm{Cu}_{2}(\mathrm{CN})_{3}$ as evidence of gapless excitations from the spin-liquid ground state $\mathrm{e}^{14}$. The subsequent thermal conductivity measurement suggested a possibility of a tiny gap of about $\Delta=0.016 J / k_{\mathrm{B}}{ }^{15}$, the origin of which is still an open question. The gapless thermal excitations observed in the heat capacity of the present salt are consistent with the thermal conductivity data obtained by Yamashita et al. ${ }^{20}$ Samples of $\kappa$-(BEDT-TTF $)_{2} \mathrm{Cu}_{2}(\mathrm{CN})_{3}$ may sometimes contain impurities due to $\mathrm{Cu}^{2+}$ and disorders depending on a difference of crystal growth conditions as is suggested in the previous works ${ }^{14,29,30}$. However, $\mathrm{EtMe}_{3} \mathrm{Sb}\left[\mathrm{Pd}(\mathrm{dmit})_{2}\right]_{2}$ samples used in the present study seem to be of better quality, judging from the smaller sample dependences and the absence of paramagnetic impurities behaviour in the magnetic field dependence. The consistency of the heat capacity and the thermal transport results ensures that the spin-liquid state realized in this compound has a gapless character.

Deuteration effects on thermodynamic properties. In order to confirm that the upturn is originated from the rotational tunnelling, we also measured the heat capacity of $\mathrm{a} \mathrm{d}_{9}-\mathrm{EtMe}_{3} \mathrm{Sb}\left[\mathrm{Pd}(\mathrm{dmit})_{2}\right]_{2}$ compound in which three Me groups in the cation had been deuterated during synthesis. As is shown in Figure 2b, the upturn was reduced down to a few percent due to the increased mass of Me groups. The residual upturn is inferred to be a trace of nondeuterated Me groups and Et groups remaining in the cations. The magnetic field dependence of the residual upturn of the deuterated compound shown in Figure $2 \mathrm{~b}$ is the same as that of the pristine compound, which also ensures that this term is arisen by rotational tunnelling. Interestingly, we found that the deuterated compound in Figure $2 \mathrm{~b}$ has a larger $C_{p} T^{-1}$ in the higher-temperature region up to about $2 \mathrm{~K}$, which should be considered separately from the contribution of Me groups. Comparison of heat capacity data of the deuterated compound and pristine compound is shown in a wider temperature scale in Figure $3 \mathrm{a}$. The temperature dependence of $C_{p} T^{-1}$ of the deuterated compound coincides well with that of the pristine compound above $2 \mathrm{~K}$; however, below this temperature, it deviates upward with decreasing temperature. This deviation is gradual and insensitive to the external magnetic field of $2 \mathrm{~T}$, but extrapolation down to $T=0$ gives a $\gamma$ of about $40 \mathrm{~mJ} \mathrm{~K}^{-2} \mathrm{~mol}^{-1}$, which is nearly twice as large as that of the pristine compound. Figure $3 \mathrm{~b}$ shows the data in the lower-temperature region under magnetic fields. The enhancement of the $\gamma$ is retained and is observed under magnetic fields up to $9 \mathrm{~T}$.

Broad hump structure in heat capacity. In the case of $\kappa$-(BEDT$\mathrm{TTF})_{2} \mathrm{Cu}_{2}(\mathrm{CN})_{3}$, the low-temperature quantum liquid state is realized below a crossover temperature of $5.7 \mathrm{~K}$, at which the heat capacity has a broad hump structure ${ }^{14}$. Recent thermal expansion measurements by Manna et al. ${ }^{31}$ indicate a clear anomaly at this temperature. Abdel-Jawad et al. ${ }^{16}$ have suggested that the unusual dielectric properties at higher temperatures are related to charge disproportionation in dimers. As shown in Figure 4a, a similar broad hump structure is observed in the $C_{p} T^{-1}$ vs $T^{2}$ curve of $\mathrm{EtMe}_{3} \mathrm{Sb}\left[\mathrm{Pd}(\mathrm{dmit})_{2}\right]_{2}$. Comparison with the data for $\mathrm{EtMe}_{3} \mathrm{P}\left[\mathrm{Pd}(\mathrm{dmit})_{2}\right]_{2}, \mathrm{EtMe}_{3} \mathrm{As}\left[\mathrm{Pd}(\mathrm{dmit})_{2}\right]_{2}$ and $\mathrm{Et}_{2} \mathrm{Me}_{2} \mathrm{Sb}\left[\mathrm{Pd}(\mathrm{dmit})_{2}\right]_{2}$ in Figure $4 \mathrm{a}$ reveals the hump structure in the $\mathrm{EtMe}_{3} \mathrm{Sb}\left[\mathrm{Pd}(\mathrm{dmit})_{2}\right]_{2}$ data. The lines in Figure 4a represent the $\beta T^{3}$ term determined from the low-temperature data below $2.0 \mathrm{~K}$ for these compounds. The $\beta$ value is $24.1 \mathrm{~mJ} \mathrm{~K}^{-4} \mathrm{~mol}^{-1}$ for $\mathrm{EtMe}_{3} \mathrm{Sb}\left[\mathrm{Pd}(\mathrm{dmit})_{2}\right]_{2}, \quad 14.3 \mathrm{~mJ} \mathrm{~K}^{-4} \mathrm{~mol}^{-1}$ for $\mathrm{EtMe}_{3} \mathrm{P}\left[\mathrm{Pd}(\mathrm{dmit})_{2}\right]_{2}$, $19.5 \mathrm{~mJ} \mathrm{~K}^{-4} \mathrm{~mol}^{-1}$ for $\mathrm{EtMe}_{3} \mathrm{As}\left[\mathrm{Pd}(\mathrm{dmit})_{2}\right]_{2}$ and $13.2 \mathrm{~mJ} \mathrm{~K}^{-4} \mathrm{~mol}^{-1}$ for $\mathrm{Et}_{2} \mathrm{Me}_{2} \mathrm{Sb}\left[\mathrm{Pd}(\mathrm{dmit})_{2}\right]_{2}$. Deviations of the experimental data of
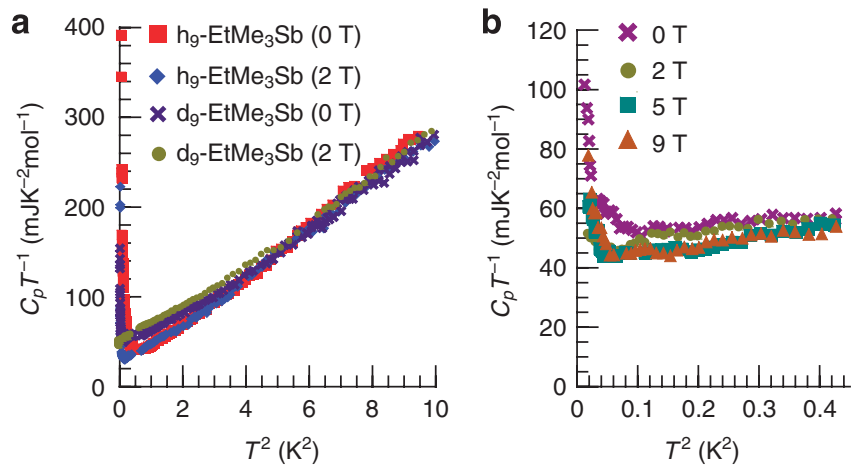

Figure 3 | Comparison of electronic heat capacity coefficient $\gamma$ between $\mathrm{EtMe}_{3} \mathbf{S b}\left[\mathrm{Pd}(\mathrm{dmit})_{2}\right]_{2}$ and $\mathrm{d}_{9}-\mathrm{EtMe}_{3} \mathbf{S b}\left[\mathrm{Pd}(\mathrm{dmit})_{2}\right]_{2^{*}}$ (a) Low-temperature heat capacities of $h_{9}-E t M e_{3} S b\left[P d(d m i t)_{2}\right]_{2}\left(h_{9}-E_{1 M e} S b\right.$; O T red squares, $2 \mathrm{~T}$ blue diamonds) and $\mathrm{d}_{9}-\mathrm{EtMe}_{3} \mathrm{Sb}\left[\mathrm{Pd}(\mathrm{dmit})_{2}\right]_{2}\left(\mathrm{~d}_{9}-\mathrm{EtMe}_{3} \mathrm{Sb}\right.$; O T purple pluses, $2 \mathrm{~T}$ ocher filled circles) below 3.1 K. Upward deviation of heat capacities of $\mathrm{d}_{9}-\mathrm{EtMe}_{3} \mathrm{Sb}\left[\mathrm{Pd}(\mathrm{dmit})_{2}\right]_{2}$ is observed below $2 \mathrm{~K}$. The enhancement of the electronic heat capacity of $\mathrm{d}_{9}-\mathrm{EtMe}_{3} \mathrm{Sb}\left[\mathrm{Pd}(\mathrm{dmit})_{2}\right]_{2}$ is realized in this temperature region. (b) Low-temperature heat capacities of $\mathrm{d}_{9}-\mathrm{EtMe}_{3} \mathrm{Sb}\left[\mathrm{Pd}(\mathrm{dmit})_{2}\right]_{2} \mathrm{O} \mathrm{T}$ (purple crosses), $2 \mathrm{~T}$ (ocher filled circles), $5 \mathrm{~T}$ (aqua blue squares) and $9 \mathrm{~T}$ (orange triangles) below $0.65 \mathrm{~K}$ plotted in $C_{p} T^{-1}$ versus $T^{2}$. The enhanced $T$-linear contribution in heat capacity does not have drastic magnetic field dependence.

$C_{p}$ from $\beta T^{3}$ are determined using the formula $\Delta C_{p}=C_{p}-\beta T^{3}$, and $\Delta C_{p} T^{-1}$ values of these compounds are plotted as a function of temperature in Figure $4 \mathrm{~b}$. The data of $\mathrm{EtMe}_{3} \mathrm{Sb}\left[\mathrm{Pd}(\mathrm{dmit})_{2}\right]_{2}$ clearly reveal the broad hump structure. Figure $4 \mathrm{~b}$ also shows additional heat capacity due to the hump in the $\kappa$-(BEDT-TTF $)_{2} \mathrm{Cu}_{2}(\mathrm{CN})_{3}{ }^{14}$ obtained by similar analysis. The hump temperature and the magnitude of the $\Delta C_{p} T^{-1}$ peak of $\mathrm{EtMe}_{3} \mathrm{Sb}\left[\mathrm{Pd}(\mathrm{dmit})_{2}\right]_{2}$ are, respectively, about $3.7 \mathrm{~K}$ and $35 \mathrm{~mJ} \mathrm{~K}^{-1} \mathrm{~mol}^{-1}$, whereas they are, respectively, $5.7 \mathrm{~K}$ and $60 \mathrm{~mJ} \mathrm{~K}^{-2} \mathrm{~mol}^{-1}$ for $\mathrm{\kappa}-(\mathrm{BEDT}-\mathrm{TTF})_{2} \mathrm{Cu}_{2}(\mathrm{CN})_{3}$. As the lattice heat capacities of organic salts do not obey the simple $\beta T^{3}$ term around the hump temperature of $\kappa$-(BEDT-TTF) ${ }_{2} \mathrm{Cu}_{2}(\mathrm{CN})_{3}, \Delta C_{p} T^{-1}$ does not reflect the correct magnetic heat capacity in this compound. The lattice heat capacity has been more accurately estimated in our previous work using the lattice heat capacities of similar $\kappa$ (BEDT-TTF $)_{2} \mathrm{X}$ compounds, and the excess entropy of the hump was estimated to be $700-1,000 \mathrm{~mJ} \mathrm{~K}^{-1} \mathrm{~mol}^{-1}$ (ref. 14). The excess entropy related to the hump in the $\mathrm{EtMe}_{3} \mathrm{Sb}\left[\mathrm{Pd}(\mathrm{dmit})_{2}\right]_{2}$ data is approximately evaluated as $70-100 \mathrm{~mJ} \mathrm{~K}^{-1} \mathrm{~mol}^{-1}$, which is $7-14 \%$ of that of $\kappa-(\mathrm{BEDT}-\mathrm{TTF})_{2} \mathrm{Cu}_{2}(\mathrm{CN})_{3}$. The hump temperatures of both salts seem to correspond to temperatures at which a small dip-like structure appears in the temperature dependences of $T_{1}^{-1}$ obtained by Itou et al. for $\mathrm{EtMe}_{3} \mathrm{Sb}\left[\mathrm{Pd}(\mathrm{dmit})_{2}\right]_{2}$ (ref. 18) and by Shimizu et al. for $\kappa-(\mathrm{BEDT}-\mathrm{TTF})_{2} \mathrm{Cu}_{2}(\mathrm{CN})_{3}$ (ref. 7). Figure $4 \mathrm{~b}$ also reveals that this hump structure of $\mathrm{EtMe}_{3} \mathrm{Sb}\left[\mathrm{Pd}(\mathrm{dmit})_{2}\right]_{2}$ does not have a magnetic field dependence up to $8 \mathrm{~T}$.

\section{Discussion}

The gapless excitations observed by the heat capacity measurements can be discussed qualitatively by assuming finite density of states in spin excitations. The temperature dependence of the magnetic susceptibility of $\mathrm{EtMe}_{3} \mathrm{Sb}\left[\mathrm{Pd}(\mathrm{dmit})_{2}\right]_{2}$ has a broad peak around $60 \mathrm{~K}$, which corresponds to a two-dimensional Heisenberg model of a triangular lattice with a magnetic interaction $-J / k_{\mathrm{B}}=220-250 \mathrm{~K}$. Extrapolating the temperature dependence of the spin susceptibility down to $T=0$ gives a residual magnetic susceptibility of $\chi(0)$. For $\mathrm{EtMe}_{3} \mathrm{Sb}\left[\mathrm{Pd}(\mathrm{dmit})_{2}\right]_{2}, \chi(0)$ is estimated to be $4.4 \times 10^{-4} \mathrm{emu} \mathrm{mol}^{-1}$ from the data obtained by Tamura et al. ${ }^{17}$ Using the value of $\gamma$ 

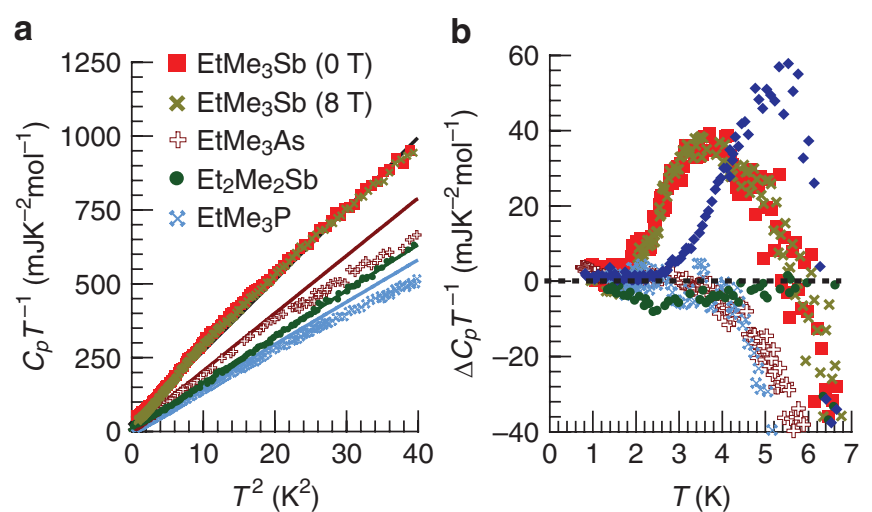

Figure 4 | Analyses of temperature dependences of the heat capacity of $\mathbf{P d}$ (dmit) ${ }_{2}$ salts. (a) $C_{p} T^{-1}$ versus $T^{2}$ plots of the heat capacity of $\mathrm{EtMe}_{3} \mathrm{Sb}\left[\mathrm{Pd}(\mathrm{dmit})_{2}\right]_{2}$ (EtMe $\mathrm{C}_{3} \mathrm{Sb}$; O T red squares, $8 \mathrm{~T}$ ocher crosses), $\mathrm{EtMe}_{3} \mathrm{As}\left[\mathrm{Pd}(\mathrm{dmit})_{2}\right]_{2}$ (EtMe $\mathrm{Es}_{3}$; O T purple pluses), Et $\mathrm{Me}_{2} \mathrm{Sb}\left[\mathrm{Pd}(\mathrm{dmit})_{2}\right]_{2}$ $\left(\mathrm{Et}_{2} \mathrm{Me}_{2} \mathrm{Sb}\right.$; OT green filled circles) and EtMe $\mathrm{P}\left[\mathrm{Pd}(\mathrm{dmit})_{2}\right]_{2}\left(\mathrm{EtMe}_{3} \mathrm{P} ; \mathrm{OT}\right.$ aqua blue crosses). The lines shown in the figure are $\beta T^{3}$ terms determined by the low-temperature data below $2.0 \mathrm{~K}$. Around 3-4K, a broad hump structure is observed only in $\mathrm{EtMe}_{3} \mathrm{Sb}\left[\mathrm{Pd}(\mathrm{dmit})_{2}\right]_{2}$. The data obtained under $8 \mathrm{~T}$ of $\mathrm{EtMe}_{3} \mathrm{Sb}\left[\mathrm{Pd}(\mathrm{dmit})_{2}\right]_{2}$ also show the hump structure. (b) The temperature dependences of $\Delta C_{p}=C_{p}-\beta T^{3}$ defined as a difference of the heat capacity data from the $\beta T^{3}$ for each compound in (a) are shown in $\Delta C_{p} T^{-1}$ vs $T$ plot. The symbols of the data are the same as those shown in (a). The data clearly indicate that the broad hump structure exists only in $\mathrm{EtMe}_{3} \mathrm{Sb}\left[\mathrm{Pd}(\mathrm{dmit})_{2}\right]_{2}$ in the $\mathrm{Pd}(\mathrm{dmit})_{2}$ system. The result of similar analysis for $\mathrm{\kappa}$-(BEDT-TTF) ${ }_{2} \mathrm{Cu}_{2}(\mathrm{CN})_{3}$ (blue diamonds) is also presented in the figure.

determined in the present study, the Wilson ratio, $R_{\mathrm{W}}$, is evaluated to be 1.09 . In the case of $\kappa$-(BEDT-TTF $)_{2} \mathrm{Cu}_{2}(\mathrm{CN})_{3}, \chi(0)$ is $2.9 \times 10^{-4} \mathrm{emu} \mathrm{mol}^{-1}$ and $\gamma$ is determined as $12.6 \mathrm{~mJ} \mathrm{~K}^{-2} \mathrm{~mol}^{-1}$ from the data in the dilution temperature region ${ }^{7,14}$, which gives an $R_{\mathrm{W}}$ of 1.13. These very similar values of $R_{\mathrm{W}}$ imply a proper scaling of $\chi(0)$ and $\gamma$ exists in the organic spin-liquid state. A Wilson ratio in the order of unity is typical for a Fermi liquid with nearly free electrons. ${ }^{13} \mathrm{C}$-NMR measurements by Itou et al. suggest a transition around $1 \mathrm{~K}$ and nodal type excitations in the spin-lattice relaxation time similar to those for $d$-wave superconductivity ${ }^{32}$. At present, it is difficult to reconcile ${ }^{13} \mathrm{C}$-NMR data with the thermodynamic data, but this discrepancy may give a further problem related to the dynamics due to the strong correlations in spin liquids.

Although the liquid-like states of the two organic salts exhibit similar thermodynamic properties, their phase diagrams surrounding the spin-liquid phase are different. Here, we discuss the difference in the $\gamma$ terms of pristine and deuterated samples of $\mathrm{EtMe}_{3} \mathrm{Sb}\left[\mathrm{Pd}(\mathrm{dmit})_{2}\right]_{2}$ in terms of the electron-phase diagram. Figure 5 shows a schematic electronic phase diagram of the $\mathrm{Pd}(\mathrm{dmit})_{2}$ system, which reveals that the spin-liquid phase occurs in a narrow region. The AF phase and CO phase are both suppressed around the spinliquid phase ${ }^{23}$. The AF phase is suppressed due to the increase in the frustration effects denoted by $t^{\prime} / t$. The point at which $T_{\mathrm{N}}$ is reduced to 0 is defined as a quantum critical point between spin-solid and liquid states. As mentioned above, the pristine $\mathrm{EtMe}_{3} \mathrm{Sb}\left[\mathrm{Pd}(\mathrm{dmit})_{2}\right]_{2}$ is located in the spin-liquid state with $t^{\prime} / t=0.92$. Deuteration of the Me groups slightly reduces the cation size and moves the electronic state from the spin-liquid region toward the $\mathrm{AF}$ region, as $\mathrm{Me}_{4} \mathrm{Sb}\left[\mathrm{Pd}(\mathrm{dmit})_{2}\right]_{2}$, which has a smaller cation, is located in the AF phase ${ }^{17}$. A possible explanation of the enhancement in the $\gamma$ term is that the deuterated compound is located very close to the critical point, which causes a critical divergence in its thermodynamic properties. In heavy-electron systems produced by strong correla-

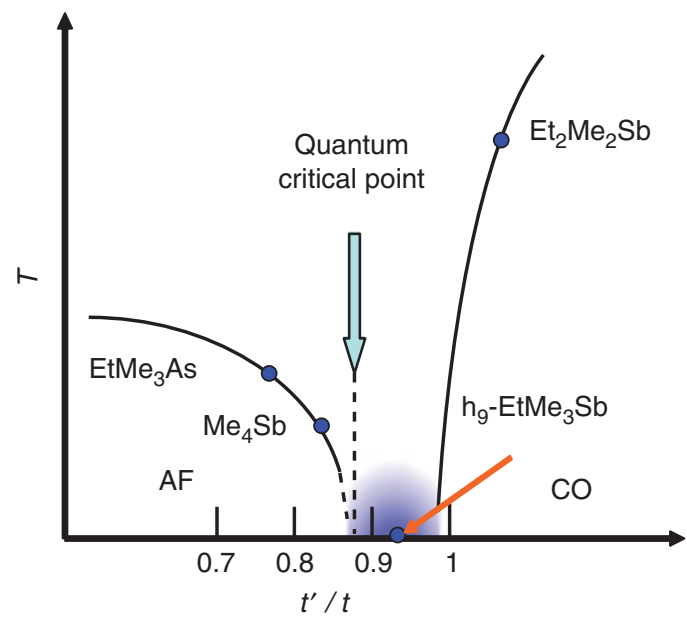

Figure 5 | A schematic view of electronic phase diagram of the $\mathrm{Pd}(\mathrm{dmit})_{2}$ system. The electronic properties of $\mathrm{Pd}(\mathrm{dmit})_{2}$ system are dominated by $t / t^{\prime}$ ratio. The spin-liquid phase is located in the narrow region between antiferromagnetic (AF) and charge order (CO) phases. The positions of $\mathrm{EtMe}_{3} \mathrm{Sb}\left[\mathrm{Pd}(\mathrm{dmit})_{2}\right]_{2}\left(\mathrm{~h}_{9}-\mathrm{EtMe}_{3} \mathrm{Sb}\right), \mathrm{EtMe}_{3} \mathrm{As}\left[\mathrm{Pd}(\mathrm{dmit})_{2}\right]_{2}\left(\mathrm{EtMe}_{3} \mathrm{As}\right)$, $\mathrm{Me}_{4} \mathrm{Sb}\left[\mathrm{Pd}(\mathrm{dmit})_{2}\right]_{2}\left(\mathrm{Me}_{4} \mathrm{Sb}\right)$ and $\mathrm{Et}_{2} \mathrm{Me}_{2} \mathrm{Sb}\left[\mathrm{Pd}(\mathrm{dmit})_{2}\right]_{2}\left(\mathrm{Et}_{2} \mathrm{Me}_{2} \mathrm{Sb}\right)$ are indicated in the figure.

tions of $f$-electrons in $\mathrm{Ce}$ and $\mathrm{U}$ compounds, anomalous divergence of $C_{p} T^{-1}$ expressed by the $-\log T$ term is known as a non-Fermi liquid behaviour at the quantum critical point ${ }^{33}$, where the AF phase is suppressed to $T_{\mathrm{N}}=0$ and an anomalous Fermi liquid phase appears. A similar kind of criticality might be expected in the critical region of a spin-liquid phase. Precise tuning of electronic properties by chemical pressures generated by partial substitution of deuterons in molecules has been achieved in the (DMe-DCNQI) ${ }_{2} \mathrm{Cu}_{\text {system }}{ }^{34}$; this should also be possible by controlling the cations in $\mathrm{Pd}(\mathrm{dmit})_{2}$ systems. Another possible explanation of this $\gamma$ enhancement is related to the nodal structure produced in the low-energy excitations in the gap. If a finite density of states at zero energy was detected as the $\gamma$ term in thermodynamic experiments, like in $d$-wave superconductivity, as is suggested by a theoretical study by Grover et al. ${ }^{35}$ and the NMR experiments ${ }^{32}$, it might be sensitive to slight changes in the chemical pressure in the spin-liquid phase. A further possible explanation is a change in the disorder potential produced by the low symmetries of cations. Although these possibilities remain speculative, the low-energy excitations in this organic spin-liquid state contain important implications for electron correlation problems peculiar to Mott-insulator triangular systems. In contrast to this complicated situation in the $\mathrm{Pd}(\mathrm{dmit})_{2}$ system, the phase diagram around the spin-liquid phase of $\kappa$-(BEDT-TTF $)_{2} \mathrm{Cu}_{2}(\mathrm{CN})_{3}$ is relatively simple and it retains a spin-liquid ground state up to $0.36 \mathrm{GPa}$ as reported by Kurosaki et al. ${ }^{36}$ Above this pressure, the spin-liquid phase undergoes a first-order transition and a superconductive phase appears ${ }^{36}$. The deuterated sample of $\kappa-\left(\mathrm{d}_{8} \text {; BEDT-TTF }\right)_{2} \mathrm{Cu}_{2}(\mathrm{CN})_{3}$ shows very similar thermodynamic behaviour as the hydrogenated samples, which is in fine contrast with the $\mathrm{EtMe}_{3} \mathrm{Sb}\left[\mathrm{Pd}(\mathrm{dmit})_{2}\right]_{2}$ system ${ }^{29}$. The presence of a quantum criticality in the spin-liquid state may have interesting implications for organic triangular compounds.

In conclusion, we have performed heat capacity measurements of single crystals of $\mathrm{EtMe}_{3} \mathrm{Sb}\left[\mathrm{Pd}(\mathrm{dmit})_{2}\right]_{2}$ and found that the lowtemperature electronic state is a gapless spin liquid. The existence of a finite $\gamma$ term in the heat capacity of $\mathrm{EtMe}_{3} \mathrm{Sb}\left[\mathrm{Pd}(\mathrm{dmit})_{2}\right]_{2}$ strongly suggests that dense gapless excitations exist in the spinliquid state. The magnitude of $\gamma$ scales to the magnetic susceptibility with a Wilson ratio of $R_{\mathrm{w}}=1.09$. The heat capacity data of $\mathrm{EtMe}_{3} \mathrm{Sb}\left[\mathrm{Pd}(\mathrm{dmit})_{2}\right]_{2}$ exhibits a small hump structure in $C_{p} T^{-1}$. These are common features with the quantum spin liquid in 
$\kappa$-(BEDT-TTF $)_{2} \mathrm{Cu}_{2}(\mathrm{CN})_{3}$. On the other hand, deuteration of the Me groups in $\mathrm{EtMe}_{3} \mathrm{Sb}\left[\mathrm{Pd}(\mathrm{dmit})_{2}\right]_{2}$ results in anomalous enhancement of the $\gamma$ term, as it is located in the critical region between $\mathrm{AF}$ and $\mathrm{CO}$ phases.

\section{Methods}

Sample preparation. The single-crystal samples used in this study were synthesized by air oxidation of $\left(\mathrm{EtMe}_{3} \mathrm{Sb}\right)_{2}\left[\mathrm{Pd}(\mathrm{dmit})_{2}\right]$ in acetone containing acetic acid at $5^{\circ} \mathrm{C}$. The deuterated crystals were prepared by the same method using $\left(\mathrm{Et}(\mathrm{CD})_{3} \mathrm{Sb}\right)_{2}\left[\mathrm{Pd}(\mathrm{dmit})_{2}\right]$. The deuterium atoms were introduced by $\mathrm{CD}_{3} \mathrm{I}(99.5 \% \mathrm{D})$.

Heat capacity measurements. Low-temperature heat capacity measurements were performed using a thermal relaxation calorimeter constructed by ourselves for measuring single crystals of molecular compounds. We used calorimetry cells that cover the temperature ranges of $0.8-10 \mathrm{~K}$ and $100 \mathrm{mK}-0.6 \mathrm{~K}$. Small-chip ruthenium oxide sensors with resistances of 10 and $1 \mathrm{k} \Omega$ at room temperature were calibrated at $0 \mathrm{~T}$ and under magnetic fields up to $10 \mathrm{~T}$. The sample stage was connected to a heat sink by eight constantan wires, each of diameter $13 \mu \mathrm{m}$. The heat leak was adjusted so as to achieve an appropriate time constant for the temperature relaxation (typically $10^{1-3} \mathrm{~s}$ ) over the whole temperature range. We used several $\mathrm{EtMe}_{3} \mathrm{Sb}\left[\mathrm{Pd}(\mathrm{dmit})_{2}\right]_{2}$ single crystals that had a total weight of $377.2 \mu \mathrm{g}$ for a ${ }^{3} \mathrm{He}$ system and $297.7 \mu \mathrm{g}$ for a dilution refrigerator system. Experiments on other salts were also performed for crystals weighing about $100 \mu \mathrm{g}$. The crystals were attached to the stage using a suitable amount of Apiezon N grease. Background heat capacities, including that of the Apiezon $\mathrm{N}$ grease, were determined by independent measurements performed before mounting the samples. The absolute heat capacities were obtained by subtracting the background values from the total heat capacity. We also measured the heat capacity of a microcrystalline sample of $\mathrm{EtMe}_{3} \mathrm{Sb}\left[\mathrm{Pd}(\mathrm{dmit})_{2}\right]_{2}$ in order to check the sample dependence.

\section{References}

1. Misguich, G. \& Lhuillier, C. in Frustrated Spin Systems (ed. Diep, H.T.) 229 (World Scientific, 2004).

2. Lee, P. A. An end to the drought of quantum spin liquids. Science 321, 1306-1307 (2008).

3. Levi, B. G. New candidate emerges for a quantum spin liquid. Phys. Today 60, 16-19 (2007).

4. Anderson, P. W. Resonating valence bonds: a new kind of insulator? Mater. Res. Bull. 8, 153-160 (1973).

5. Coldea, R., Tennant, D. A., Tsvelik, A. M. \& Tylczynski, Z. Experimental realization of a 2D fractional quantum spin liquid. Phys. Rev. Lett. 86, 1335-1338 (2001)

6. Nakatsuji, S. et al. Spin disorder on a triangular lattice. Science 309, 1697-1700 (2005).

7. Shimizu, Y., Miyagawa, K., Kanoda, K., Maesato, M. \& Saito, G. Spin liquid state in an organic Mott insulator with a triangular lattice. Phys. Rev. Lett. 91, 1007001 (2003).

8. Ramirez, A. P., Hessen, B. \& Winklemann, M. Entropy balance and evidence for local spin singlets in a kagomé-like magnet. Phys. Rev. Lett. 84, 2957-2960 (2000).

9. Hiroi, Z. et al. Spin-1/2 kagomé - like lattice in volborthite $\mathrm{Cu}_{3} \mathrm{~V}_{2} \mathrm{O}_{7}(\mathrm{OH})_{2} 2 \mathrm{H}_{2} \mathrm{O}$. J. Phys. Soc. Jpn. 70, 3377-3384 (2001)

10. Shores, M. P., Nytko, E. A., Bartlett, B. M. \& Nocera, D. G. A structurally perfect S-1/2 kagomé antiferromagnet. J. Am. Chem. Soc. 127, 13462-13463 (2005).

11. Okamoto, Y., Yoshida, H. \& Hiroi, Z. Vesignieite $\mathrm{BaCu}_{3} \mathrm{~V}_{2} \mathrm{O}_{8}(\mathrm{OH})_{2}$ as a candidate spin-1/2 kagome antiferromagnet. J. Phys. Soc. Jpn. 78, 033701 (2009).

12. Okamoto, Y., Nohara, M., Aruga-Katori, H. \& Takagi, H. Spin-liquid state in the $S=1 / 2$ hyperkagome antiferromagnet $\mathrm{Na}_{4} \mathrm{Ir}_{3} \mathrm{O}_{8}$. Phys. Rev. Lett. 99, 137207 (2007).

13. Balents, L. Spin liquids in frustrated magnets. Nature 464, 199-208 (2010).

14. Yamashita, S. et al. Thermodynamic properties of a spin-1/2 spin-liquid state in a א-type organic salt. Nat. Phys. 4, 459-462 (2008).

15. Yamashita, M. et al. Thermal-transport measurements in a quantum spin-liquid state of the frustrated triangular magnet $\kappa-(\text { BEDT-TTF })_{2} \mathrm{Cu}_{2}(\mathrm{CN})_{3}$. Nat. Phys. 5, 44-47 (2009).

16. Abdel-Jawad, M. et al. Anomalous dielectric response in the dimer Mott insulator $\kappa$-(BEDT-TTF) ${ }_{2} \mathrm{Cu}_{2}(\mathrm{CN})_{3}$. Phys. Rev. B82, 125119 (2010).

17. Tamura, M. \& Kato, R. Magnetic susceptibility of $\beta^{\prime}-\left[\mathrm{Pd}(\mathrm{dmit})_{2}\right]$ salts (dmit $=1$, 3-dithiol-2-thione-4, 5-dithiolate, $\mathrm{C}_{3} \mathrm{~S}_{5}$ ): evidence for frustration in spin-1/2 Heisenberg antiferromagnets on a triangular lattice. J. Phys.: Condens. Matter 7, L729-L734 (2002).

18. Itou, T., Oyamada, A., Maegawa, S., Tamura, M. \& Kato, R. Quantum spin liquid in the spin-1/2 triangular antiferromagnet $\mathrm{EtMe}_{3} \mathrm{Sb}\left[\mathrm{Pd}(\mathrm{dmit})_{2}\right]_{2}$. Phys. Rev. B 77, 104413 (2008)

19. Itou, T., Oyamada, A., Maegawa, S., Tamura, M. \& Kato, R. ${ }^{13}$ C NMR study of the spin-liquid state in the triangular quantum antiferromagnet $\mathrm{EtMe}_{3} \mathrm{Sb}\left[\mathrm{Pd}(\mathrm{dmit})_{2}\right]_{2}$. J. Phys. Conf. Ser. 145, 012039 (2009).
20. Yamashita, M. et al. Highly mobile gapless excitations in a two-dimensional candidate quantum spin liquid. Science 328, 1246-1248 (2010).

21. Kato, R. Conducting metal dithiolene complexes: structural and electronic properties. Chem. Rev. 104, 5319-5346 (2004).

22. Tajima, H. et al. Energy level inversion in strongly dimerized $\left[\mathrm{Pd}(\mathrm{dmit})_{2}\right]$ salts. Solid State Commun. 79, 337-341 (1991).

23. Shimizu, Y., Akimoto, H., Tsujii, H., Tajima, A. \& Kato, R. Reentrant Mott transition from a Fermi liquid to a spin-gapped insulator in an organic spin-1/2 triangular-lattice antiferromagnet. J. Phys. Condens. Mat. 19, 145240 (2007)

24. Kato, R., Tajima, A., Nakano, A., Tajima, N. \& Tamura, M. in Multifunctional Conducting Molecular Materials (ed. Saito, G. et al.) 32-38 (The Royal Society of Chemistry, 2007).

25. Tamura, M., Nakao, A. \& Kato, R. Frustration-induced valence-bond ordering in a new quantum triangular antiferromagnet based on $\left[\mathrm{Pd}(\mathrm{dmit})_{2}\right]$. J. Phys. Soc. Jpn. 75, 093701 (2006)

26. Kato, R., Tajima, A., Nakao, A. \& Tamura, M. Two pressure-induced superconducting anion radical salts exhibiting different spin states at ambient pressure. J. Am. Chem Soc. 128, 10016-10017 (2006).

27. Tamura, M. et al. Spectroscopic evidence for the low-temperature chargeseparated state of $\left[\mathrm{Pd}(\mathrm{dmit})_{2}\right]$ salts. Chem. Phys Lett. 411, 133-137 (2005).

28. Sorai, M., Murakawa, S., Kotani, T. \& Suga, H. Heat capacity of a cubanetetramer, $\left[\mathrm{Ni}\left(\mathrm{OCH}_{3}\right)(\mathrm{SAL})\left(\mathrm{CH}_{3} \mathrm{OH}\right)\right]_{4}$, between 0.4 and $288 \mathrm{~K}$ : spin-spin interactions and tunnel-splitting of the internal rotation of methyl-groups. J. Phys. Chem. Solids 44, 1133-1139 (1983).

29. Yamashita, S., Yamamoto, T. \& Nakazawa, Y. Low temperature heat capacity measurements of the spin-liquid states of hydrogenated and deuterated $\kappa$ (BEDT-TTF $)_{2} \mathrm{Cu}_{2}(\mathrm{CN})_{3}$. Physica B 405, S240-S243 (2010).

30. Komatsu, T., Matsukawa, N., Inoue, T. \& Saito, G. Realization of superconductivity at ambient pressure by band-filling control in $\kappa$ - (BEDTTTF $)_{2} \mathrm{Cu}_{2}(\mathrm{CN})_{3}$. J. Phys Soc. Jpn. 65, 1340-1354 (1996).

31. Manna, R. S., de Souza, M., Brühl, A., Schlueter, J. A. \& Lang, M. Lattice effects and entropy release at the low-temperature phase transition in the spin-liquid candidate $\kappa$-(BEDT-TTF $)_{2} \mathrm{Cu}_{2}(\mathrm{CN})_{3}$. Phys. Rev. Lett. 104, 016403 (2010).

32. Itou, T., Oyamada, A., Maegawa, S. \& Kato, R. Instability of a quantum spin liquid in an organic triangular-lattice antiferromagnet. Nat. Phys. 6, 673-676 (2010).

33. Löhneysen, H. V. et al. Non-Fermi-liquid behavior in a heavy-Fermion alloy at a magnetic instability. Phys. Rev. Lett. 72, 3262-3265 (1994).

34. Kato, R. Conductive copper salts of 2,5-disubstituted N,N'dicyanobenzoquinonediimines (DCNQIs): structural and physical properties. Bull. Chem. Soc. Jpn. 73, 515-534 (2000).

35. Grover, T., Trivedi, N., Senthil, T. \& Lee, P. A. Weak Mott insulators on the triangular lattice: possibility of a gapless nematic quantum spin liquid. Phys. Rev. B 81, 245121 (2010).

36. Kurosaki, Y., Shimizu, Y., Miyagawa, K., Kanoda, K. \& Saito, G. Mott transition from a spin liquid to a Fermi liquid in the spin-frustrated organic conductor К-(ET) ${ }_{2} \mathrm{Cu}_{2}(\mathrm{CN})_{3}$. Phys. Rev. Lett. 95, 177001 (2005)

\section{Acknowledgments}

We thank Prof. Y. Nishio at Toho University for giving us an opportunity to measure the heat capacity of the EtMe $e_{3} \mathrm{As}\left[\mathrm{Pd}(\mathrm{dmit})_{2}\right]_{2}$ sample. We also thank Prof. H. Nojiri and Dr. Y. Oshima at IMR, Tohoku University for their support in the experiments by a dilution refrigerator. This work was partially supported by a Grant-in-Aid on Priority Area 'Novel States of Matter Induced by Frustration (22014007)', a Grant-in-Aid for Scientific Research (No. 20110003) from the Ministry of Education, Science, Sports and Culture of Japan and a Grant-in-Aid for Scientific Research (No. 22340098) from the Japan Society for the Promotion of Science. One of the authors (S.Y.) thanks the fellowship from the Global Education and Research Center for Bio-Environmental Chemistry of Osaka University

\section{Author contributions}

S.Y., T.Y. and Y.N. carried out the thermodynamic measurements, data analysis and discussion. M.T. and R.K. prepared samples and gave information from structural analyses and susceptibility experiments.

\section{Additional information}

Competing financial interests: The authors declare no competing financial interests.

Reprints and permission information is available online at http://npg.nature.com/ reprintsandpermissions/

How to cite this article: Yamashita, S. et al. Gapless spin liquid of an organic triangular compound evidenced by thermodynamic measurements. Nat. Commun. 2:275 doi: $10.1038 /$ ncomms1274 (2011)

License: This work is licensed under a Creative Commons Attribution-NonCommercialShare Alike 3.0 Unported License. To view a copy of this license, visit http:// creativecommons.org/licenses/by-nc-sa/3.0/ 